\title{
Paper of the June Issue of Stem Cell Reviews and Reports Provides Further Evidence that Tissue Physiological Low Oxygen Tension in Contrast to Atmospheric Ambient Oxygen Tension Enhances Competence and Functional Properties of Stem Cells
}

\author{
Mariusz Z. Ratajczak ${ }^{1}$ \\ Published online: 26 April 2021 \\ (C) The Author(s), under exclusive licence to Springer Science+Business Media, LLC, part of Springer Nature 2021
}

In this June issue of Stem Cell Reviews and Reports, Robi AR. Bolli et al. report that cardiac tissue physiological oxygen tension $\left(5 \% \mathrm{O}_{2}\right)$ in contrast to atmospheric oxygen one $(21 \%$ $\mathrm{O}_{2}$ ) enhances competence and functional properties of cardiac mesenchymal cells (CMCs) [1]. These cells are a newly discovered promising type of progenitor cells, which, as demonstrated, turned out to be effective in improving cardiac function in rodents after myocardial infarction [2].

This exciting and potentially clinically relevant for stem cell therapies paper raises again the importance of "Extra Physiological Oxygen Shock Stress" (EPHOSS) that has been reported a few years ago by Dr. Hall Broxmeyer group to occur in the case of hematopoietic stem cells (HSCs) [3]. This group proposed that HSCs that reside in bone marrow at $3 \% \mathrm{O}_{2}$ if exposed to atmospheric ambient $21 \% \mathrm{O}_{2}$, rapidly lose their "stemness" due to their differentiation into progenitor cells. Therefore, as postulated while working with HSCs, it is important to avoid exposure of collected cells to ambient air conditions, as even short exposure of HSCs to ambient $21 \% \mathrm{O}_{2}$ level may change the biology of these cells that in steady state conditions reside in bone marrow at around $3 \%$ $\mathrm{O}_{2}$. This effect, as demonstrated, is related to EPHOSSmediated increase in mitochondria permeability and release of reactive oxygen species (ROS) [4].

Similarly, as in BM, stem/progenitor cells in the heart reside in an environment that is characterized by low $\sim 5 \% \mathrm{O}_{2}$ tension and EPHOSS may affect fate of these cells. In the elegant paper published in this June issue of Stem Cell Reviews and Reports, Robi RA Bolli et al. reports that CMCs at $5 \% \mathrm{O}_{2}$ in contrast to CMCs cultured at $21 \% \mathrm{O}_{2}$ consistently maintained their morphology, increased in

Mariusz Z. Ratajczak

mariusz.ratajczak@louisville.edu

1 University of Louisville, Louisville, KY, USA number, shortened cell doubling time, and increased telomerase activity and telomere length [1]. Since almost all preclinical and clinical studies of cell therapy in cardiology, similarly as in hematology, employ atmospheric $(21 \%) \mathrm{O}_{2}$ to harvest and culture ex vivo cells, low $\mathrm{O}_{2}$ tension would enhance the competence and functional properties of CMCs and HSCs.

What is important, data published in this issue of Stem Cell Reviews and Reports shows that the increased proliferation rate of $\mathrm{CMCs}$ at $5 \% \mathrm{O}_{2}$ shows that the required number of CMCs for potential therapeutic applications can be achieved with much less time and cost. Furthermore, as postulated, this increased proliferation of CMCs may continue in vivo after $\mathrm{CMC}$ transplantation, and CMCs grown at $5 \% \mathrm{O}_{2}$ are markedly resistant to severe hypoxic stress, they would be able to survive better after transplantation which will enhance their reparative properties even in highly hypoxic areas of damaged myocardium $\left(\sim 1 \% \mathrm{O}_{2}\right)$.

This very intriguing paper supporting further the phenomenon of EPHOSS in stem cell therapies would benefit from addressing ROS's potential role in activation of intracellular innate immunity pattern recognition receptor Nlrp3 inflammasome in CMCs, that if hyperactivated, may lead to cell damage and eventually their pyroptosis [5]. This is a highly inflammatory form of lytic programmed cell death that occurs in response to intracellular danger signals. One of the assays to detect pyroptosis is to measure lactate dehydrogenase (LDH) release from the cells. As reported in this July issue paper, authors, in fact, observed an increase in LDH activity in media from $\mathrm{CMCs}$ cultured at $21 \% \mathrm{O}_{2}$. Simultaneously, LDH activity was detectable at a much lower level in CMCs cultures at $5 \% \mathrm{O}_{2}$. It is well known that $\mathrm{ROS}$ are potent activators of this Nlrp3 inflammasome and that ROS are released from mitochondria in response to EPHOSS [3]. Therefore, ROS scavengers or small molecular inhibitors of Nlrp3 inflammasome (e.g., MCC950) could mitigate the negative consequences of EPHOSS. This, however, 
requires further experimental studies both in the case of $\mathrm{CMCs}$ and HSCs as finally, cell damaging mechanisms triggered by EPHOSS could still be different for these cells. To explain this, HSCs studied by Dr. Broxmeyer group are more primitive from a developmental point of view $[3,4]$ than CMCs that were investigated in the current report published in Stem Cell Reviews and Reports [1]. Nevertheless, regardless of the final mechanism involved, stem/progenitor cells "do not like" EPHOSS that affects their fate, and we should help them to avoid this unnecessary challenge [1-5].

\section{References}

1. Bolli, R. A., Dasari, C., Arshia, A., et al. (2021). Physiological oxygen tension enhances competence and functional properties of murine cardiac mesenchymal cells. Stem Cell Rev and Rep. https://doi. org/10.1007/s12015-020-10106-6.
2. Wysoczynski, M., Guo, Y., Moore, J. B., Muthusamy, S., Li, Q., Nasr, M., et al. (2017). Myocardial reparative properties of cardiac mesenchymal cells isolated on the basis of adherence. Journal of the American College of Cardiology, 69(14), 1824-1838.

3. Broxmeyer, H. E., O'Leary, H. A., Huang, X., \& Mantel, C. (2015 Jul). The importance of hypoxia and extra physiologic oxygen shock/stress for collection and processing of stem and progenitor cells to understand true physiology/pathology of these cells ex vivo. Current Opinion in Hematology, 22(4), 273-278.

4. Mantel, C. R., O'Leary, H. A., Chitteti, B. R., Huang, X., Cooper, S., Hangoc, G., Brustovetsky, N., Srour, E. F., Lee, M. R., MessinaGraham, S., Haas, D. M., Falah, N., Kapur, R., Pelus, L. M., Bardeesy, N., Fitamant, J., Ivan, M., Kim, K. S., \& Broxmeyer, H. E. (2015 Jun 18). Enhancing hematopoietic stem cell transplantation efficacy by mitigating oxygen shock. Cell., 161(7), 1553-1565.

5. Zheng, M., \& Kanneganti, T. D. (2020 Sep). The regulation of the ZBP1-NLRP3 inflammasome and its implications in pyroptosis, apoptosis, and necroptosis (PANoptosis). Immunological Reviews, 297(1), 26-38.

Publisher's Note Springer Nature remains neutral with regard to jurisdictional claims in published maps and institutional affiliations. 